\title{
Seletividade do Atrazine À Cultura do Milheto (Pennisetum glaucum) ${ }^{1}$
}

\author{
Atrazine Selectivity in Pearl Millet (Pennisetum glaucum)
}

\author{
DAN, H.A. ${ }^{2}$, BARROSO, A.L.L. ${ }^{3}$, PROCÓPIO, S.O. ${ }^{4}$, DAN, L.G.M. ${ }^{5}$, FINOTTI, T.R. ${ }^{6}$ e \\ ASSIS, R.L. ${ }^{3}$
}

\begin{abstract}
RESUMO - O milheto é uma espécie de destaque entre aquelas cultivadas em sucessão na região dos cerrados brasileiros. Embora o herbicida atrazine apresente potencial para ser utilizado nessa cultura, pouco tem sido feito para determinar a suscetibilidade dessa espécie em função do seu estádio de desenvolvimento no momento de aplicação. Objetivou-se com este trabalho avaliar a seletividade do herbicida atrazine à cultura do milheto (Pennisetum glaucum), determinando a dosagem máxima de aplicação e os estádios da cultura que apresentem menor sensibilidade. Foram realizados dois ensaios em casa de vegetação, onde se determinou primeiramente a seletividade do herbicida para os cultivares ADR-300, ADR-500 e ADR-7010. Posteriormente, o cultivar ADR-500 foi avaliado em condições de dose-resposta do atrazine, em função do estádio fenológico de desenvolvimento. Este experimento foi realizado no delineamento inteiramente casualizado, em esquema fatorial $5 \times 3$, com quatro repetições, correspondendo a cinco doses de atrazine: 0; 0,5; 1,5; 2,5 e 4,0 kg de i.a. ha ${ }^{-1}$, aplicadas em três estádios de crescimento do milheto (duas, quatro e oito folhas expandidas). O cultivar ADR-500 apresentou a maior suscetibilidade entre os avaliados. Aplicações realizadas nos estádios mais precoces de crescimento do milheto promoveram os maiores niveis de intoxicação, redução do número de afilhos e do acúmulo de biomassa seca da parte aérea. Essses resultados intensificaram-se com o incremento da dose de atrazine. Com relação à massa da espiga, doses inferiores a $1,5 \mathrm{~kg} \mathrm{ha}^{-1}$ não prejudicaram significativamente essa variável, independentemente do estádio de aplicação. É possivel concluir que doses inferiores a $1,5 \mathrm{~kg} \mathrm{ha}^{-1}$ de atrazine podem ser usadas de forma segura na cultura do milheto quando as plantas apresentarem quatro ou mais folhas no momento da aplicação.
\end{abstract}

Palavras-chave: herbicida, triazinas, pós-emergência, cultivares de milheto.

ABSTRACT - Pearl millet is an important species cultivated in succession in the Brazilian savannah. Although the herbicide atrazine presents a potential use in this culture, little has been done to determine the susceptibility of this species according to its stage of development at the time of application. This study aimed to evaluate the selectivity of atrazine to millet (Pennisetum glaucum), determining the maximum dosage of implementation and the culture stages with lower sensitivity. Two experiments were conducted under greenhouse conditions, by first establishing the selectivity of the herbicide to cultivars ADR-300, ADR-50O and ADR-7010. Subsequently, cultivar ADR-500 was evaluated in terms of dose response of atrazine during the phenological stage of development. The experiment was arranged in a completely randomized design in a factorial scheme $5 \times 3$, with four replications, corresponding to five atrazine doses $\left(0 ; 0.5 ; 1.5 ; 2.5\right.$ and $4.0 \mathrm{~kg}$ a.i. ha $\left.\mathrm{a}^{-1}\right)$ applied at three millet growth stages (two, four and eight expanded leaves). ADR-500 cultivar showed the highest susceptibility among the cultivars evaluated. Applications made at the early stages of millet growth promoted the highest levels of phytotoxicity symptoms, reducing the number of shoots and

Recebido para publicação em 23.12.2009 e na forma revisada em 17.12.2010

2 Discente do Programa de Pós-Graduação em Agronomia, Universidade Estadual de Maringá - UEM/NAPD, Av. Colombo 5790, 87020-900 Maringá-PR, <halmeidadan@gmail.com>; ${ }^{3}$ Professores da Faculdade deAgronomia, Universidade de Rio Verde-FESURV, Caixa Postal 104, 75901-970 Rio Verde-GO, ${ }^{4}$ Pesquisador, Embrapa Tabuleiros Costeiros, 49025-040 Aracaju-SE; ${ }^{5}$ Mestranda, Programa de Pós-Graduação em Agronomia, Universidade Estadual de Maringá - UEM; ${ }^{6}$ Graduando em Agronomia, FESURV.

Planta Daninha, Viçosa-MG, v. 28, p. 1117-1124, 2010. Número Especial 
dry biomass accumulation of the aerial part. These results were intensified by increasing the atrazine dose. With respect to ear mass, doses less than $1.5 \mathrm{~kg} \mathrm{ha}^{-1}$ did not significantly affect this variable, regardless of the stage of application. It was concluded that atrazine doses below $1.5 \mathrm{~kg} \mathrm{ha}^{-1}$ can be safely applied on growing millet, when the plants present four or more leaves at the time of application.

Keywords: herbicides, triazines, post-emergence, pearl millet cultivars

\section{INTRODUÇÃO}

O milheto (Pennisetum glaucum) constituise em uma espécie forrageira que pode ser utilizada tanto na alimentação animal quanto na humana (grãos) (Scaléa, 1998). É uma gramínea muito cultivada nas regiões de clima tropical, sendo considerada uma planta de ciclo anual, de hábito de crescimento ereto, porte alto, com desenvolvimento uniforme e bom perfilhamento, mesmo em condições de baixa disponibilidade hídrica (Kissmann, 1997).

Devido à sua grande adaptação ao bioma dos cerrados, vem ganhando destaque nos últimos anos, principalmente com a chegada de híbridos de alto potencial produtivo, oriundos do melhoramento genético. Isso fez com que essa planta deixasse de ser uma simples espécie de cobertura ou de produção de palha para o plantio direto, passando a ser considerada uma cultura de valor econômico para produção de grãos e forragem, tornando-se difundida nessa região.

Apesar da rusticidade, essa espécie apresenta crescimento inicial lento, tornando-se vulnerável à interferência causada pela matointerferência (pela competição com as plantas daninhas). Nesse contexto, as plantas daninhas podem ser um fator limitante para o desenvolvimento da cultura. Segundo Carson (1987), o não controle destas durante o período crítico de competição, que vai até sete semanas após a emergência do milheto, pode reduzir a produtividade de grãos em até $36 \%$. Para Berglund (1998), o controle de plantas daninhas nessa cultura deve ser realizado ainda na fase inicial, pois as plantas de milheto só começam a tolerar a presença de plantas daninhas ao atingirem de 15 a $20 \mathrm{~cm}$ de altura.

Como na maioria das espécies cultivadas, o controle químico é uma ferramenta imprescindivel para o manejo integrado de plantas daninhas em regiões onde predominam grandes extensões de cultivo. Embora seja uma espécie que vem ganhado destaque na região dos cerrados, não existe no mercado brasileiro nenhum herbicida registrado para uso na cultura do milheto. Mesmo para culturas de grande expressão, como o milho, a disponibilidade atual de herbicidas seletivos é limitada.

Atrazine é um herbicida que pode apresentar potencial de uso na cultura do milheto (Dan et al., 2009). Possui mecanismo de ação que envolve a inibição do transporte de elétrons no fotossistema II. Apresenta seletividade em aplicações em pré ou em pós-emergência para as culturas do milho e sorgo (Silva et al., 2007) - espécies cultivadas pertencentes à mesma familia do milheto. Pesquisas demonstram a eficácia do atrazine no controle das plantas daninhas tanto em aplicações isoladas (Fornarolli et al., 1999; Maciel et al., 2002), como em associações com outros herbicidas, como mesotrione (Timossi, 2009) e nicosulfuron (Rizzardi et al., 2008).

Apesar de o herbicida atrazine ser considerado atualmente uma referência para o controle químico de plantas daninhas, principalmente latifoliadas, nas culturas do milho e sorgo, são escassas as informações referentes à sua seletividade para o milheto, sobretudo para os cultivares mais modernos, incluindo híbridos, que vêm mudando o perfil de utilização dessa cultura. Alguns trabalhos avaliaram a seletividade de outros herbicidas à cultura do milheto. Farinelli et al. (2005) e Pacheco et al. (2007) observaram que o herbicida 2,4-D apresentou seletividade aceitável em aplicações de pós-emergência na cultura do milheto. Da mesma forma, Lyon et al. (2007) verificaram que o herbicida carfentrazoneethyl apresentou segurança para uso na cultura do milheto. 
Com base nesse contexto, objetivou-se com este trabalho avaliar a seletividade do herbicida atrazine aplicado em pós-emergência da cultura do milheto, determinando dosagem máxima de aplicação e os estádios da cultura que apresentem menor sensibilidade.

\section{MATERIAL E MÉTODOS}

Os experimentos foram conduzidos em casa de vegetação no campus da Faculdade de Agronomia da Universidade de Rio Verde FESURV, em Rio Verde-GO, localizada nas coordenadas de $17^{\circ} 48^{\prime} \mathrm{S}, 55^{\circ} 55^{\prime} \mathrm{W}$ e altitude de $760 \mathrm{~m}$, durante o período de maio a novembro de 2008.

Foram utilizadas para confecção das unidades experimentais amostras de um Latossolo Vermelho distroférrico de textura argilosa, coletadas na camada de 20 a $40 \mathrm{~cm}$ de profundidade. As características químicas e físicas da amostra do solo foram: $\mathrm{pH}$ em água: 4,4; Ca: 1,36 $\mathrm{cmol}_{\mathrm{c}} \mathrm{dm}^{-3}$; $\mathrm{Mg}: 0,73 \mathrm{cmol}_{\mathrm{c}} \mathrm{dm}^{-3}$; Al: $0,45 \mathrm{cmol}_{\mathrm{c}} \mathrm{dm}^{-3} ; \mathrm{H}+\mathrm{Al}: 4,8 \mathrm{cmol}_{\mathrm{c}} \mathrm{dm}^{-3}$; $\mathrm{K}: 65 \mathrm{mg} \mathrm{dm}^{-3}$; P: 2,07 $\mathrm{mg} \mathrm{dm}^{-3}$; CTC: $16,6 \mathrm{cmol}_{\mathrm{c}} \mathrm{dm}^{-3}$; MO: 21,67 $\mathrm{g} \mathrm{kg}^{-1}$; argila: $600 \mathrm{~g} \mathrm{~kg}^{-1}$; silte: $50 \mathrm{~g} \mathrm{~kg}^{-1}$; e areia: $350 \mathrm{~g} \mathrm{~kg}^{-1}$.

A correção da acidez do solo foi realizada 30 dias antes da semeadura do milheto, utilizando-se o equivalente a 1,78 tonelada de calcário dolomítico (PRNT 98\%) por hectare. No momento da semeadura, realizou-se uma adubação de base com $60 \mathrm{~kg} \mathrm{ha}^{-1}$ de $\mathrm{P}_{2} \mathrm{O}_{5}$ (superfosfato simples), $20 \mathrm{~kg} \mathrm{ha}^{-1}$ de $\mathrm{K}_{2} \mathrm{O}$ (cloreto de potássio) e $20 \mathrm{~kg} \mathrm{ha}^{-1}$ de nitrogênio (sulfato de amônia).

O primeiro experimento foi implantado em vasos com $10 \mathrm{dm}^{3}$ de solo e conduzido em delineamento inteiramente casualizado com seis repetições, em esquema fatorial $3 \times 2$, correspondendo a três cultivares de milheto (ADR-300, ADR-500 e ADR-7010), submetidos a duas doses de atrazine (Atrazina Nortox 500 $\left.\mathrm{SC}^{\circledR}\right): 0$ e 1,5 kg de i.a. ha ${ }^{-1}$. Foi adicionado à calda de aplicação do herbicida $0,25 \% \mathrm{v} / \mathrm{v}$ do óleo mineral Attach ${ }^{\circledR}$. Os tratamentos foram aplicados no estádio fenológico de quatro folhas completamente expandidas, cerca de 21 dias após a emergência da cultura (DAE).

A semeadura foi realizada a $1,5 \mathrm{~cm}$ de profundidade. Sete dias após a emergência, as plântulas foram desbastadas, sendo mantidas três plantas por unidade experimental. A irrigação foi realizada conforme a necessidade da cultura.

A aplicação do herbicida foi feita com pulverizador costal com pressurização por $\mathrm{CO}_{2}$, munido de quatro pontas de pulverização do tipo TT 110-02 (barra de $2 \mathrm{~m}, 0,5 \mathrm{~m}$ entre pontas), utilizando um volume de calda equivalente a $100 \mathrm{~L} \mathrm{ha}^{-1}$. As condições ambientais durante a aplicação foram: temperatura média de $25,1{ }^{\circ} \mathrm{C}$, UR média de $81 \%$ e velocidade média do vento de $2,1 \mathrm{~km} \mathrm{~h}^{-1}$.

Avaliações de fitointoxicação foram realizadas aos 7, 15 e 21 dias após a aplicação dos tratamentos (DAA), utilizando-se escala percentual de 0 a $100 \%$, em que 0 representa ausência de sintomas e $100 \%$ a morte de todas as plantas, segundo a escala da Alam (1974). Aos 38 DAE, determinou-se ainda a biomassa seca da parte aérea; antes da pesagem, a parte aérea das plantas foi cortada rente ao solo e seca em estufa com circulação de ar a $65^{\circ} \mathrm{C}$ durante um periodo de 72 horas.

Os resultados referentes aos niveis de fitointoxicação e biomassa seca foram submetidos à transformação $(\sqrt{ } \mathrm{x}+1)$, visando atender aos pressupostos necessários para a análise de variância, utilizando-se o programa estatístico Sisvar. As médias das variáveis significativas foram comparadas pelo teste de Tukey a $5 \%$ de probabilidade.

O segundo ensaio foi conduzido em vasos de $10 \mathrm{dm}^{3}$ de solo, em delineamento inteiramente casualizado com quatro repetições, em esquema fatorial $5 \times 3$, correspondendo a cinco doses de atrazine (Atrazina Nortox $500 \mathrm{SC}^{\circledR}$ ): $0 ; 0,5 ; 1,5 ; 2,5 ;$ e 4,0 kg de i.a. ha ${ }^{-1}$, aplicados em três estádios fenológicos das plantas de milheto cv. ADR-500: estádio 1 (plantas com duas folhas expandidas, 15 dias após a emergência); estádio 2 (plantas com quatro folhas expandidas, cerca de 21 dias após a emergência); e estádio 3 (plantas com oito folhas expandidas e com um a dois afilhos, cerca de 28 dias após a emergência). Em todos os tratamentos herbicidas foi adicionado à calda $0,5 \% \mathrm{v} / \mathrm{v}$ do óleo mineral Attach ${ }^{\circledR}$.

A semeadura do milheto ocorreu a $1,5 \mathrm{~cm}$ de profundidade, sendo o desbaste realizado aos 7 DAE, mantendo-se uma densidade de duas 
plantas por unidade experimental. A irrigação foi realizada conforme a necessidade da cultura.

A aplicação dos tratamentos herbicidas foi realizada com pulverizador costal com pressurização por $\mathrm{CO}_{2}$, munido de quatro pontas de pulverização do tipo TT 110-02 (barra de $2 \mathrm{~m}, 0,5 \mathrm{~m}$ entre pontas), utilizando um volume de calda equivalente a $100 \mathrm{~L} \mathrm{ha}^{-1}$. As condições ambientais no momento das aplicações eram as seguintes: estádio 1 - temperatura média de $21,1{ }^{\circ} \mathrm{C}$, UR média de $83 \%$ e velocidade média do vento de $2,9 \mathrm{~km} \mathrm{~h}^{-1}$; estádio 2 - temperatura média de $25,2{ }^{\circ} \mathrm{C}$, UR média de $77 \%$ e velocidade média do vento de $4,5 \mathrm{~km} \mathrm{~h}^{-1}$ ); e estádio 3 - temperatura média de $26,7^{\circ} \mathrm{C}$, UR média de $74 \%$ e velocidade média do vento de $3,1 \mathrm{~km} \mathrm{~h}^{-1}$. Todas as aplicações foram iniciadas no mesmo horário (7h30), justamente devido às melhores condições para aplicação. A irrigação foi retomada 24 horas após a aplicação dos tratamentos, com o intuito de evitar perdas do herbicida por lavagem foliar.

Avaliações de fitointoxicação foram realizadas aos 7, 14 e 21 dias após a aplicação dos tratamentos (DAA), utilizando-se escala percentual de 0 a $100 \%$, em que 0 representa ausência de sintomas e $100 \%$ a morte de todas as plantas, segundo a escala da Alam (1974). Foi determinada ainda a altura das plantas (medida com uma trena graduada, considerando a distância entre o colo da planta e a extremidade final da última folha) aos 50 DAE. Aos 60 DAE, foi determinado o número de afilhos por planta e, no final da fase reprodutiva, obteve-se a biomassa seca da parte aérea e o peso das espigas (sem o pedúnculo).

Os resultados referentes aos niveis de fitointoxicação foram submetidos a uma transformação $(\sqrt{ }+1)$, a fim de atender aos pressupostos necessários para a realização da análise de variância, utilizando-se o programa estatístico Sisvar. Foram ajustados modelos lineares de regressão para as variáveisresposta quantitativas que apresentaram significância, empregando-se o programa Sigma Plot versão 10.0 para confecção das curvas de regressão. A fim de ampliar a visualização dos resultados, as médias da variável massa das espigas foram comparadas pelo teste de Tukey a $5 \%$ de probabilidade.

\section{RESULTADOS E DISCUSSÃO}

\section{Experimento 1}

Houve interação significativa para os diferentes cultivares de milheto quando submetidos à dose de $1,0 \mathrm{~kg} \mathrm{ha}^{-1}$ de atrazine, para as variáveis fitointoxicação e biomassa seca da parte aérea. Aos 15 dias após a aplicação do herbicida (DAA) (Tabela 1), observouse leve clorose nas folhas, sendo de maior intensidade sobre o cultivar ADR-500. Durante esse periodo, todos os cultivares apresentaram fitointoxicação significativa em relação às plantas que não receberam o herbicida, sendo a intensidade dos sintomas variável entre 11 e $18 \%$. Apesar desses resultados, todos os cultivares mostraram recuperação dos efeitos iniciais do herbicida, não sendo constatados sintomas de fitointoxicação aos 21 DAA (dados não apresentados). Dowler \& Wright (1995) verificaram baixa tolerância do milheto ao atrazine, propachlor e pendimethalin aplicados em pré-emergência, isoladamente ou mesmo em misturas. Por sua vez, Dan et al. (2009) observaram bons niveis de seletividade em aplicações realizadas na pós-emergência dessa cultura.

Quanto ao acúmulo de biomassa seca da parte aérea, avaliado aos 38 dias após a aplicação de atrazine (Tabela 1), constataramse efeitos negativos da aplicação do herbicida em todos os cultivares avaliados. Maior redução da biomassa seca da parte aérea foi observada no cultivar ADR-500 (8,25\%). Não

Tabela 1 - Fitointoxicação e porcentagem de redução da biomassa seca da parte aérea (BSPA) em cultivares de milheto aos 15 e 38 dias após a aplicação do herbicida atrazine, respectivamente

\begin{tabular}{|c|c|c|c|c|}
\hline \multirow{2}{*}{ Cultivar } & \multicolumn{3}{|c|}{ Fitointoxicação (\%) } & \multicolumn{2}{c|}{ Redução da BSPA (\%) } \\
\cline { 2 - 5 } & \multicolumn{4}{|c|}{ Dose (kg ha $\left.{ }^{-1}\right)$} \\
\cline { 2 - 5 } & 0 & 1,5 & 0 & 1,5 \\
\hline ADR-300 & $0,0 \mathrm{aB}$ & $11,5 \mathrm{bA}$ & $0,0 \mathrm{aB}$ & $3,75 \mathrm{bA}$ \\
\hline ADR-500 & $0,0 \mathrm{aB}$ & $18,3 \mathrm{aA}$ & $0,0 \mathrm{aB}$ & $8,25 \mathrm{aA}$ \\
\hline ADR-7010 & $0,0 \mathrm{aB}$ & $13,5 \mathrm{bA}$ & $0,0 \mathrm{aB}$ & $2,13 \mathrm{bA}$ \\
\hline CV (\%) & \multicolumn{3}{|c|}{13,3} & \multicolumn{2}{c}{8,21} \\
\hline DMS & 4,52 (coluna) $\mathrm{e}$ & 2,32 (coluna) $\mathrm{e}$ \\
& 3,69 (linha) & 2,22 (linha) \\
\hline
\end{tabular}

Médias seguidas de mesma letra (minúscula na coluna e maiúscula na linha) não diferem entre si pelo teste de Tukey $(\mathrm{p} \geq 0,05)$. 
foi verificada diferença significativa em relação ao acúmulo de biomassa entre ADR-300 e o hibrido de milheto ADR-7010, após a aplicação de atrazine.

\section{Experimento 2}

Houve interação significativa entre as doses de atrazine e os estádios de desenvolvimento do milheto cv. ADR 500, em relação às avaliações de fitointoxicação.

Dentro do intervalo de doses estudado, observou-se inicialmente, aos 7 dias após a aplicação (DAA), que os niveis de fitointoxicação máximos apresentados pela cultura foram de 65, 26 e 23\%, respectivamente, para aplicações realizadas nos estádios 1,2 e 3, mostrando que os maiores níveis de injúria foram obtidos em aplicações mais precoces (Figura 1A). Esses resultados mantiveram a mesma tendência aos 14 DAA (dados não apresentados).

Aos 21 DAA, as plantas de milheto apresentaram injúrias em menor intensidade, indicando a intensa capacidade de recuperação da espécie; no entanto, os valores de fitointoxicação seguiram a mesma tendência, isto é, aplicações realizadas em estádios mais precoces de desenvolvimento apresentaram maiores taxas de incremento de fitointoxicação (Figura 1B).

Comparando os coeficientes angulares dos modelos lineares ajustados aos 21 DAA (Figura 1B), observa-se que, embora em todos os casos a porcentagem de fitointoxicação seja diretamente relacionada à dose aplicada de atrazine, plantas que receberam o herbicida no estádio 1 apresentaram incrementos sobre a porcentagem de fitointoxicação numa taxa aproximadamente quatro vezes maior do que aqueles que receberam a aplicação no estádio 3 , evidenciando a maior sensibilidade da espécie em aplicações muito precoces.

Durante o período de avaliação, os sintomas mais evidentes apresentados pelas plantas de milheto foram clorose internervural seguida de necrose nos bordos das folhas, o que, segundo Weller (2003), são sintomas característicos dos herbicidas pertencentes ao grupo dos inibidores do fotossistema II. Em plantas mais sensiveis essa sintomatologia pode ser expressiva logo aos quatro dias após a aplicação.

Apesar de a injúria apresentar-se em função da dose e do estádio das plantas no momento da aplicação, o milheto mostrou grande tolerância ao atrazine, principalmente nos estádios mais avançados de desenvolvimento. Segundo Silva et al. (2007), esse aumento na tolerância das gramineas é mais perceptivel quando elas se encontram em estádios mais avançados. Esse fato pode estar relacionado à menor absorção de herbicidas através dos tecidos foliares e/ou ao aumento de compostos detoxificadores, como as benzoxazinonas, substâncias capazes de proporcionar reações como hidroxilação, dealquilação e até mesmo
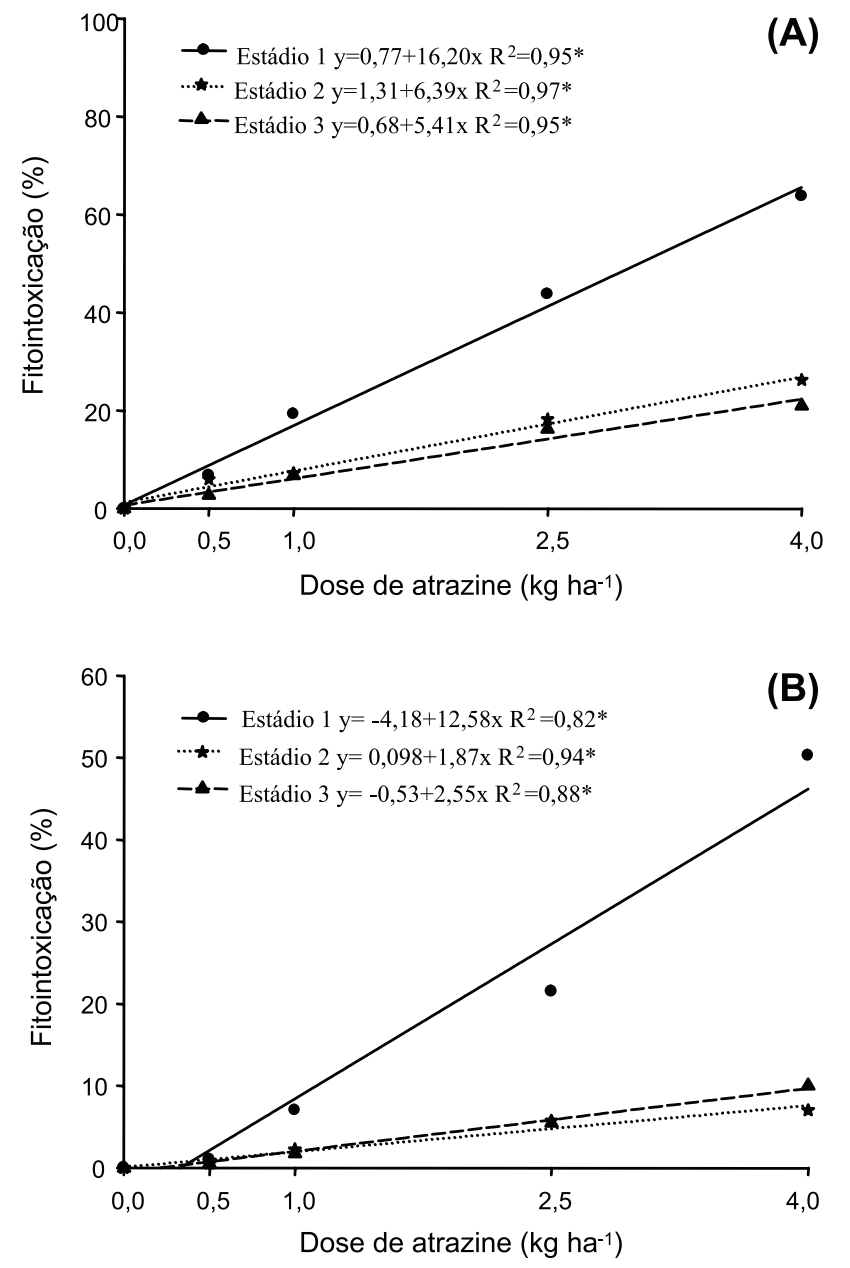

Figura 1 - Fitointoxicação em plantas de milheto aos 7 (A) e 21 (B) dias após a aplicação (DAA) de diferentes doses de atrazine em três estádios da cultura, no momento da aplicação. 
conjugação, reduzindo a atividade do herbicida. Para Marcacci et al. (2005), o citocromo P-450 é o grande responsável pela dealquilação do herbicida atrazine em plantas tolerantes. Prado et al. (1995) constataram que a seletividade de atrazine a Panicum dichotomiflorum ocorreu devido ao processo de conjugação das moléculas herbicidas com os compostos cisteína e glutationa.

Além do estádio das plantas no momento da aplicação, é possivel que existam diferenças marcantes entre espécies pertencentes à família Poaceae no que se refere à intoxicação provocada por atrazine. Martins et al. (2007) observaram que Brachiaria brizantha possui maior sensibilidade à atrazine do que Brachiaria decumbens. Jakelaitis et al. (2005) verificaram que plantas de Digitaria horizontalis mostraram baixa suscetibilidade ao atrazine aplicado em área sob o sistema de integração lavoura-pecuária.

Com relação à altura das plantas de milheto, a utilização de atrazine apresentou maior potencial supressor quando a aplicação ocorreu no estádio mais precoce do milheto (Figura 2). Observa-se que no estádio 1 a redução na altura das plantas foi diretamente proporcional à dose utilizada na aplicação. Em aplicações tardias (estádios 2 e 3) essa variável foi pouco influenciada. É importante frisar que a altura das plantas é um fator primordial no processo de colheita dos grãos, já que na região dos cerrados essa espécie é colhida mecanicamente.

Os efeitos relacionados à ação do herbicida nas plantas não se restringiram apenas à altura delas. É possível observar ainda que a elevação da dose reduziu substancialmente o perfilhamento das plantas (Figura 3). Plantas livres da ação do herbicida chegaram a produzir de quatro a cinco afilhos, decrescendo numa taxa de 0,73, 0,61 e 0,47 para o incremento de cada $\mathrm{kg}$ do herbicida para os estádios 1, 2 e 3, respectivamente. Em função desses valores, é possivel inferir que aplicações mais tardias apresentam menores efeitos sobre esse aspecto biológico da espécie.

É interessante salientar que a quantidade de afilhos viáveis pode ser um fator determinante em se tratando do acúmulo de biomassa e número de estruturas reprodutivas, uma vez que as plantas com maior número de afilhos eventualmente terão capacidade de produzir maior número de espigas, que é um dos principais componentes do rendimento da cultura.

Ao analisar o comportamento dos percentuais de acúmulo na biomassa seca da parte aérea em relação aos valores obtidos pela testemunha (Figura 4), constatou-se que as maiores reduções foram obtidas quando a aplicação do herbicida ocorreu no estádio 1 . Esse fato pode estar relacionado à maior fitointoxicação causada pelo herbicida; o acréscimo de cada $\mathrm{kg}$ de herbicida proporcionou decréscimo de $12,9 \%$ na biomassa seca acumulada na parte aérea durante todo o ciclo de

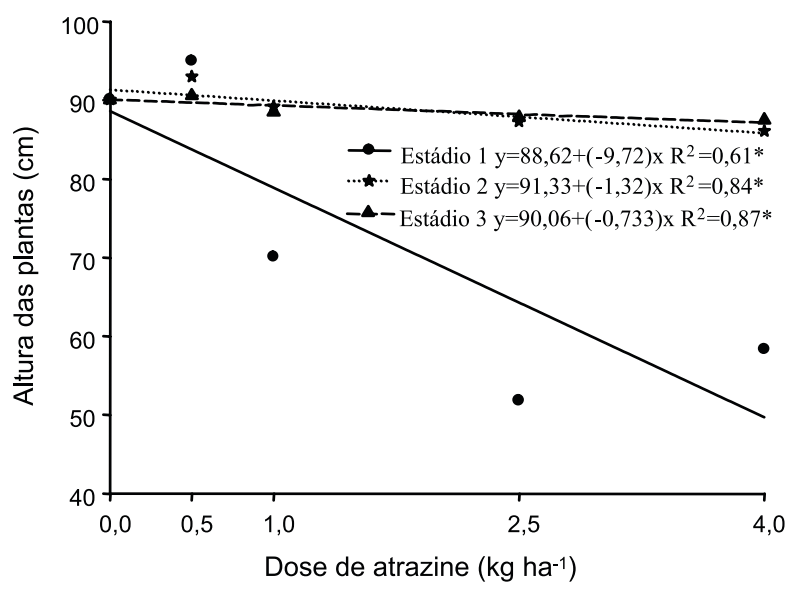

Figura 2 - Altura das plantas de milheto aos 50 dias após a emergência (DAE), em função da dose de atrazine e do estádio da planta no momento da aplicação.

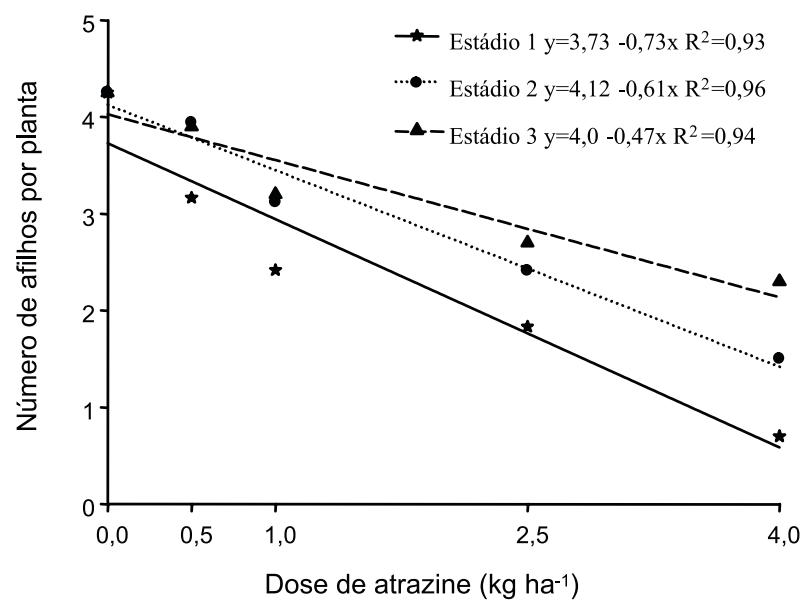

Figura 3 - Número de afilhos por planta de milheto aos 60 dias após a emergência, em função da dose de atrazine e do estádio da planta no momento da aplicação. 


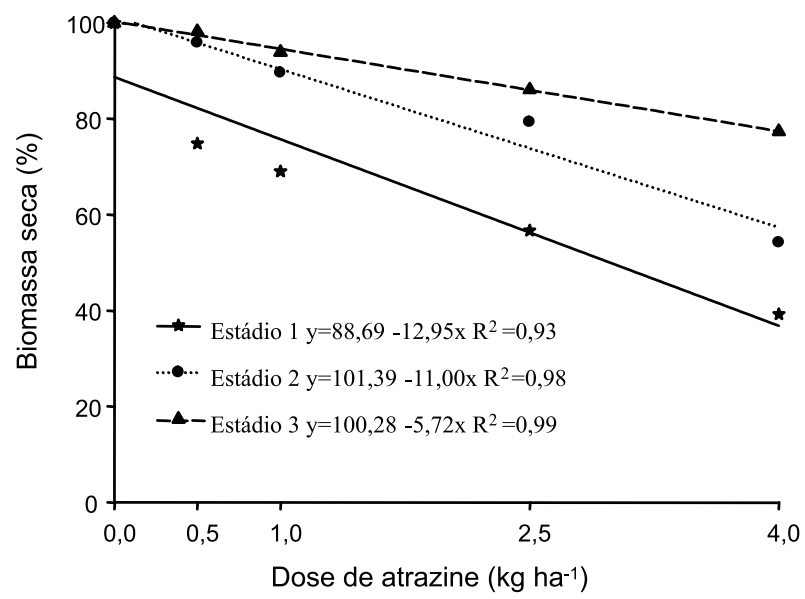

Figura 4 - Acúmulo de biomassa seca na parte aérea de plantas de milheto (\% em relação à testemunha), em função da dose de atrazine e do estádio da planta no momento da aplicação.

vida da planta. No estádio 3, essa redução foi de apenas 5,7\%. Esse pode ser um fator negativo para quem trabalha com milheto visando à produção de forragem, havendo assim necessidade de maior cautela com relação à dose e ao estádio de utilização desse herbicida.

Uma das explicações mais plausíveis para o menor acúmulo de biomassa seca da parte aérea pode ser a redução da área foliar sinteticamente ativa, já que o referido herbicida inibe ou suprime todo o aparato fotossintético localizado no fotossistema II, dificultando a transferência de elétrons, a produção de fotoassimilados e, consequentemente, o acúmulo de biomassa.

No que se refere aos aspectos relacionados ao rendimento de grãos, as plantas de milheto apresentaram reduções expressivas quando submetidas a doses crescentes de atrazine (Figura 5). Comparando os coeficientes angulares dos modelos lineares ajustados, observa-se, dentro do intervalo de doses estudado, que valores máximos de redução no rendimento da cultura foram de 56, 39 e 32\%, respectivamente, para aplicações realizadas nos estádios 1, 2 e 3, ou seja, as reduções foram mais expressivas nas aplicações realizadas precocemente, intensificando-se com o incremento da dose.

Embora: uso do modelo linear evidencie reduções significativas sobre a massa das espigas de milheto, o teste de média aplicado

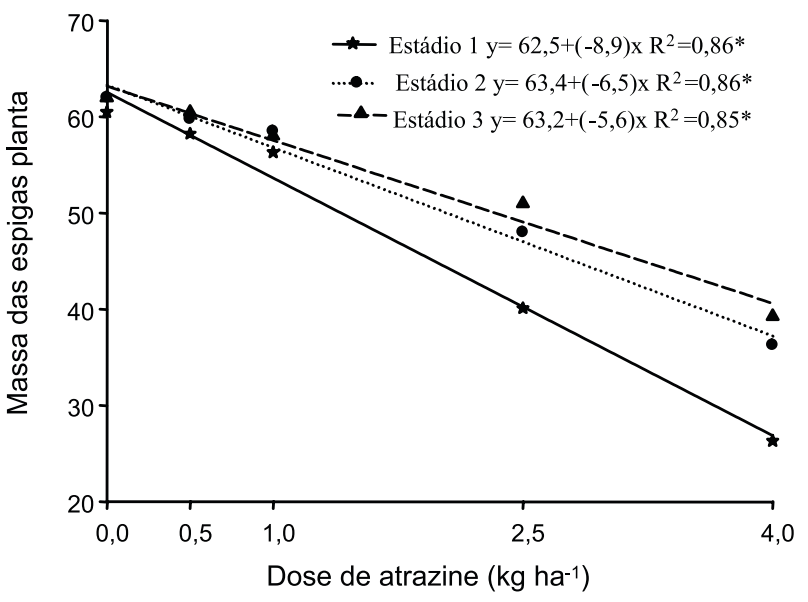

Figura 5 - Massa da espiga de plantas de milheto (\% em relação à testemunha), em função da dose e da época de aplicação de atrazine.

sobre a variável-resposta mostra que a utilização de até $1,5 \mathrm{~kg} \mathrm{ha}^{-1}$ de atrazine não causou redução significativa dessa variável em aplicações realizadas nos estádios 1, 2 e 3 (Tabela 2), mostrando que doses inferiores a esta podem ser usadas de forma segura visando ao manejo de plantas daninhas na cultura do milheto. No entanto, doses superiores a $2,5 \mathrm{~kg} \mathrm{ha}^{-1}$ do herbicida proporcionaram reduções significativas no rendimento da cultura, independentemente do estádio utilizado para aplicação. Esse resultado está de acordo com o verificado por Ndhai et al. (1980), que, avaliando a seletividade de vários herbicidas do grupo das triazinas, concluíram que o milheto mostrou-se tolerante ao herbicida atrazine aplicado em pós-emergência somente quando

Tabela 2 - Massa da espiga de plantas de milheto (g) obtida em função da dose e da época de aplicação de atrazine

\begin{tabular}{|c|c|c|c|}
\hline \multirow{2}{*}{$\begin{array}{c}\text { Dose de atrazine } \\
\left(\mathrm{kg} \mathrm{ha}^{-1}\right)\end{array}$} & \multicolumn{3}{|c|}{ Massa da espiga (g) } \\
\cline { 2 - 4 } & Estádio 1 & Estádio 2 & Estádio 3 \\
\hline 0,0 & $60,70 \mathrm{aA}$ & $62,12 \mathrm{aA}$ & $62,12 \mathrm{aA}$ \\
\hline 0,5 & $58,60 \mathrm{aA}$ & $59,75 \mathrm{aA}$ & $60,50 \mathrm{aA}$ \\
\hline 1,5 & $56,27 \mathrm{aA}$ & $58,50 \mathrm{aA}$ & $58,50 \mathrm{aA}$ \\
\hline 2,5 & $40,52 \mathrm{bB}$ & $48,07 \mathrm{bA}$ & $51,00 \mathrm{bA}$ \\
\hline 4,0 & $26,02 \mathrm{cB}$ & $36,15 \mathrm{cA}$ & $39,05 \mathrm{cA}$ \\
\hline $\mathrm{CV}(\%)$ & \multicolumn{3}{|c}{4,67} \\
\hline
\end{tabular}

Médias seguidas de mesma letra (minúscula na coluna e maiúscula na linha) não diferem entre si pelo teste de Tukey $(\mathrm{p} \geq 0,05)$. DMS: 4,87(estádio) e 4,01 (dose). 
se utilizou a metade da dose recomendada para a cultura do milho.

De acordo com os resultados, é possivel concluir que doses inferiores a $1,5 \mathrm{~kg} \mathrm{ha}^{-1} \mathrm{de}$ atrazine podem ser usadas de forma segura na cultura do milheto quando as plantas apresentarem quatro ou mais folhas no momento da aplicação.

\section{LITERATURA CITADA}

BERGLUND, D. R. Proso millet in North Dakota. Fargo: North Dakota State University, 1998. 7 p.

CARSON, A. G. Improvement weed management in the draft animal-based production of early pearl millet in Gambia

Trop. Pest Manag., v. 33, n. 2, p. 359-363, 1987

DAN, H. A. et al. Seletividade de herbicidas aplicados na pósemergência da cultura do milheto (Pennisetum glaucum).

R. Bras. Milho e Sorgo, v. 8, n. 3, p. 297-306, 2009

DOWLER, C. C.; WRIGHT, D. L. Weed management systems for pearl millet in the southestern United States. In NATIONAL GRAIN PEARL MILLETS, 1., 1995, Tifton. Proceedings...Tifton: University of Georgia, 1995. p. 64-71.

FARINELLI, R.; PENARIOL, F. G.; LEMOS, L. B. Eficiência do herbicida 2,4-D no controle de Raphanus raphanistrum $\mathrm{L}$. em pós-emergência na cultura do milheto. R. Bras. Milho Sorgo, v. 4, n. 1, p. 104-111, 2005.

FORNAROLLI, D. A. et al. Influência do horário de aplicação no comportamento de atrazine e misturas aplicadas em pósemergência na cultura do milho. Planta Daninha, v. 17, n. 1, p. 119-120, 1999.

JAKELAITIS, A. et al. Efeitos de herbicidas no consórcio de milho com Brachiaria brizantha.

Planta Daninha, v. 23, n. 1, p. 69-78, 2005

KISSMANN, K. G. Plantas infestantes e nocivas. São Paulo: BASF, 1997. p. 675-678. Tomo I.

LYON, D. J. et al. Carfentrazone improves broadleaf weed control in proso and foxtail millets. Weed Technol., v. 21, n. 1, p. $84-87,2007$
MACIEL, C. D. G. et al. Método alternativo para avaliação da absorção de atrazine por plantas de Brachiaria plantaginea. Planta Daninha, v. 20, n. 3, p. 431-438, 2002.

MARCACCI, S. et al. The possible role of hydroxylation in the detoxification of atrazine in mature vetiver (Chrysopogon zizanioides Nash) grown in hydroponics. J. Biosci., v. 60, n. 5, p. 427-34, 2005.

MARTINS, D. et al. Seletividade de herbicidas aplicados em pós-emergência sobre capim-braquiária. R. Bras. Zootec., v. 36, n. 2, p. 1969-1974, 2007.

NDAHI, W. B. et al. Growth of pearl millet (Pennisetum americanum (L.) Leeke) as influenced by selected herbicide applications and delay in planting. In: VANDERLIP, R. L. (Ed.) IMPROVEMENT OF PEARL MILLET. SECOND ANNUAL REPORT. Manhattan: Kansas State University, 1980. p. $67-71$.

PACHECO, L. P. et al. Tolerância do milheto (Pennisetum americanum) ao 2,4-D. Planta Daninha, v. 25, n. 1, p. 173-179, 2007.

PRADO, R. et al. Atrazine detoxification in Panicum dichotomiflorum and target site Polygonum lapathifolium.

Pest. Biochem. Physiol., v. 52, n. 1, p. 1-11, 1995.

RIZZARDI, M. A. et al. Controle de plantas daninhas em milho em função de épocas de aplicação de nitrogênio. Planta Daninha, v. 26, n. 1, p. 113-121, 2008.

SCALÉA, M. J. Perguntas \& respostas sobre o plantio direto Inf. Agron., v. 83, p. 1-8, 1998.

SILVA, A. A. et al. Herbicidas: classificação e mecanismo de ação. In: SILVA, A. A.; SILVA, J. F. (Eds.). Tópicos em manejo de plantas daninhas. Viçosa, MG: Universidade Federal de Viçosa, 2007. p. 83-148.

TIMOSSI, P. C. Manejo de rebrotes de Digitaria insularis no plantio direto de milho. Planta Daninha, v. 27, n. 1, p. $175-179,2009$.

WELLER, S. Photosystem II inhibitors. In: Herbicide action course. West Lafayette: Purdue University, 2003. p. $131-184$ 